\title{
Article \\ Emergency Repair Scheduling Model for Road Network Integrating Rescheduling Feature
}

\author{
Shu-Shun Liu ${ }^{1, *}$, Muhammad Faizal Ardhiansyah Arifin ${ }^{2,3}$, Wei Tong Chen ${ }^{1}\left(\mathbb{D}\right.$ and Ying-Hua Huang ${ }^{1}(\mathbb{D}$ \\ 1 Department of Civil and Construction Engineering, National Yunlin University of Science and Technology, \\ Yunlin 640, Taiwan; chenwt@yuntech.edu.tw (W.T.C.); huangyh@yuntech.edu.tw (Y.-H.H.) \\ 2 Graduate School of Engineering Science and Technology, National Yunlin University of Science and Technology, \\ Yunlin 640, Taiwan; D10610211@gemail.yuntech.edu.tw \\ 3 Department of Civil Engineering, Universitas Negeri Semarang, Sekaran Gunungpati, \\ Semarang 50229, Indonesia \\ * Correspondence: liuss@yuntech.edu.tw; Tel.: +886-928-512-520
}

\section{check for}

updates

Citation: Liu, S.-S.; Arifin, M.F.A.; Chen, W.T.; Huang, Y.-H. Emergency Repair Scheduling Model for Road Network Integrating Rescheduling Feature. Appl. Sci. 2021, 11, 1447. https://doi.org/10.3390/app11041447

Academic Editor: Igal M. Shohet

Received: 31 December 2020

Accepted: 2 February 2021

Published: 5 February 2021

Publisher's Note: MDPI stays neutral with regard to jurisdictional claims in published maps and institutional affiliations.

Copyright: (c) 2021 by the authors. Licensee MDPI, Basel, Switzerland. This article is an open access article distributed under the terms and conditions of the Creative Commons Attribution (CC BY) license (https:// creativecommons.org/licenses/by/ $4.0 /)$.

\begin{abstract}
When a natural disaster occurs, road maintenance departments always face the challenge of how to assign repair resources properly to recover damaged road segments as soon as possible. From the literature review, most studies treat such problems as a vehicle routing problem (VRP). In those studies, repair resources are always dispatched as complete crews, and cannot be divided into smaller scales. Furthermore, each disaster point is only allowed one group of resources to recover it, without considering the possibility of accelerating the production rate subjected to specific objectives. Such limitation restricts required resources in an inflexible manner. Therefore, this study defines all repair works as an emergency repair project and adopts the framework of the Resource-Constrained Project Scheduling Problem (RCPSP), which can resolve such complicated resource assignment issue. A novel emergency repair scheduling model for the road network is proposed based on Constraint Programming (CP) as the searching algorithm to facilitate model formulation. According to the RCPSP concepts, disaster points are set as repair activities and resource travel routes between disaster points are set as transit activities. All the repair activities are linked by transit activities and the required resources are assigned accordingly. In order to consider the second-wave hazard events of where new disaster points may occur, and new resources may be added into emergency repair projects, a rescheduling feature is integrated into the proposed model. Through two case studies, research findings show that this model can be easily modulated to adapt to different situations satisfying practical disaster management goals and solving emergency repair scheduling problems for road networks efficiently.
\end{abstract}

Keywords: road network; emergency repair; project scheduling; rescheduling; constraint programming

\section{Introduction}

The strike of a devastating hazard event causes significant damage to the road network and creates a chaotic situation [1-4]. Thus, effective disaster management in this chaotic post disaster situation becomes an inevitable demand to overcome post disaster problems and ensure road network functionality [5,6]. In disaster management, there are four relevant phases which include mitigation, preparedness, response, and recovery [6,7]. The response phase is the execution of an emergency procedure and utilizes all necessary resources to recover all disaster-affected communities back to normal life [5]. Moreover, the response phase is not only conducted by air, but also absolutely relies on road networks (highways, tunnels, and bridges) to support survivor evacuation, rescue operations, and societal recovery [8-10].

Maintenance units always prepare for the challenge of how to effectively allocate emergency repair resources (work crews or equipment) to recover damaged facilities in their areas of responsibility so that rescue and supplies can be brought into disaster areas 
more quickly. Significant damage to road networks always makes rescue and supplies distribution difficult for the affected locations [11] and delays the evacuation of survivors to shelter [12]. Such unavoidable conditions did happen in the post disaster event of the Chi-Chi earthquake that occurred in Taiwan, on 21 September 1999, where the affected population which lived in villages were isolated because of the damaged roads and no bypasses in mountain terrain [13]. The same post disaster situation also occurred in the Wenchuan earthquake in Sichuan Province, China, on 12 May 2008, which destructed a road network of $53 \mathrm{~km}$ and made many impacted villages isolated [14]. Learning from past experiences, people in the affected disaster area need to be rescued immediately. A delay in distribution logistics and medical aid can lead to an increasing number of death casualties [15]. Thus, a quick post disaster response to perform an emergency repair of damaged road networks in a short time is crucially significant [11,16].

There are some key challenges to performing emergency repair scheduling in the chaotic situation of the aftermath of a disaster, compared to routine maintenance scheduling. From previous research, those challenges are elaborated as follows [17-22]: (1) an unpredictable situation because of inaccurate information, (2) difficulties to perform ideal communication and coordination among the involved humanitarian relief parties, (3) the available resources are often overwhelmed compared to the scale of the chaotic situation (e.g., food supply, manpower, vehicle capacity, heavy equipment, fuel, and medicines), (4) high probability of second-wave threats, and (5) the sequence of repair activities.

Therefore, the repair schedule must satisfy the following two characteristics: First, although the number and location of available repair equipment resources within the maintenance unit's area of responsibility are known, under the condition of limited resources, the productivity of repair equipment resources must be coordinated by the decision maker before allocation, so that the schedule can adapt to real disaster conditions and improve the efficiency of the repair project with the best resource allocation [22,23]; second, due to the topography or geographic location, not all damaged facilities are directly connected to the location of repair resources, which will be called a "resource point" later, so the sequence of repair activities at disaster points must take into account the limitations of the actual area and complete the overall repair project as soon as possible [24,25].

Inspired by those challenges and the necessity of emergency repair scheduling for road networks, this study proposes an optimization model for emergency repair scheduling problems, based on a framework of the Resource-Constrained Project Scheduling Problem (RCPSP). Repair activity execution involves the possession of repair resources and the determination of the available quantity of all usable repair resources. Therefore, an emergency repair scheduling problem handled by maintenance units during the response phase is essentially a good application to the RCPSP, in which the decision maker schedules all repair works and integrates the resources of various crew and engineering equipment to conduct the emergency operation. The conceptual idea of this model starts with identifying the damaged road sections to obtain preliminary data from the first strike of disaster, and then, the decision maker can determine the demand for all kinds of repair resources based on the target time to recover the damage of the whole road network. Based on the initial assessment of damage status, the proposed model then establishes the first emergency repair schedule for the road network. When the second-wave hazard events come, new disaster points will be generated, and the new damage status needs to be updated. Those unexpected events force the decision maker to make a corresponding decision for the adjustment to fulfill the new repair needs. Under such dynamic circumstances, this study intends to provide a rescheduling feature to rearrange all existing repair activities adjusted to the new condition after second-wave hazard events.

The following section gives a review of the major contributions in the literature on emergency repair scheduling of the road network and the resource-constrained project scheduling problem (RCPSP). Section 3 presents the conceptual idea and model formulation of the proposed model. Section 4 provides two cases and four scenarios to demonstrate the 
application of the proposed model. Finally, Section 5 concludes research contributions and future works.

\section{Literature Review}

Due to the significant impact of natural disasters, there is no single assessment measure alone that can fully describe the road network destruction caused by natural disasters. To generalize possible road damage conditions, they can be categorized in the following three levels [26]:

1. Total destruction, if the road embankment needs to be reconstructed.

2. Partial damage, if the road section is closed for road surface repairs or minor stabilization of the road embankment.

3. Only sedimentation on the road surface that does not require any repair work.

For example, Keaton et al. [27] reported the severe damage that occurred in Los Angeles County, California, which was caused by a winter storm in 2005, hit by rockfalls and debris slides. Most road damages that occurred in Taiwan shared similar terrestrial characteristics to the case study of [27]. Therefore, the repair activity defined in this study is excavation work for rockfall and debris slides in the partial damage condition level.

Based on the four aforementioned phases of disaster management, post disaster repair scheduling can be divided into two types: long-term recovery for restoring the whole road network performance and short-term recovery to restore the roadway functionalities in order to support the relief distribution in terms of emergency repair [10,16]. Kaviani et al. [28] confirmed in the pre-event of a disaster, road network performance is in a normal condition. When the disaster event occurs, the road network's performance suddenly drops into an unserviceable condition, until the post disaster confusion phase ends. Following the post disaster confusion phase, the response stage performs emergency repair to recover the road network to a minimally serviceable condition for relief distribution and other humanitarian activities. The recovery phase started simultaneously with the response phase after the post disaster event until the road network's performance returned to a normal condition. This study deals with the issues of short-term emergency repair.

The maximum target time for the emergency response period after a disaster is in three days [29] and more time can be in seven days depending on the scale of the event [28]. Thus, the challenge of establishing a reliable emergency resource schedule (ERS) to recover the functionalities of the road network is receiving great attention from academics as well as public sectors.

In the past decade, there were several studies proposed for road network repair schedules and logistic relief distribution for emergency response phases in post disaster recovery. Most studies employed the Vehicle Routing Problem (VRP) approach to solve the emergency repair scheduling problem. Campbell et al. [30] developed an optimization model that was based on the traveling salesman problem (TS) and VRP utilizing Mixed Integer Programming (MIP) that minimizes the maximum arrival time and the average arrival time of delivery relief logistics to the disaster area. Wohlgemuth et al. [19] solved pickups and delivery problems as an extension of classical VRP to plan the last mile of the relief distribution chain. A multi-stage mixed-integer programming approach was deployed to avoid delays in the delivery of time-critical relief logistics. Huang et al. [31] developed an Assessment Routing Problem (ARP) model based on VRP concepts to minimize the sum of arrival times of distribution relief at the affected communities, by applying the tabu search heuristic algorithm. Another VRP approach was proposed by Zhong et al. [32] to select vehicle routes and vehicle quantity based on the active distribution center and the relief demand in each disaster point. This optimization model was solved with a hybrid genetic algorithm (GA).

Maya and Sorensen [33] proposed a repair plan for the road network during recovery phases under scarce resources based on the Greedy randomized adaptive search procedure (GRASP) and Variable Neighborhood Search (VNS) to maximize the communities' accessibility in the affected disaster location. Furthermore, Aksu and Ozdamar [12] attempted to 
restore blocked links in a road network during the first three days of emergency response under resource constraints using an integer programming model in the Debris Clearance Scheduling Model (DCSM). Improved from the previous model [31], Maya et al. [34] developed a framework called Network Repair Crew Scheduling and Routing Problem (NRCSRP) in terms of a road network to minimize the traveling movement of a repair crew in opening the access from disaster location to the relief center. This method is identical to the concept of VRP with utilizing iterated greedy-randomized constructive procedure (IGRCP). Based on their works, Kim et al. [35] utilized the Ant Colony System (ACS) algorithm to develop an optimization model for solving NRCSRP in the disaster response phase for short-term disaster; this model is called network repair crew scheduling for short-term disaster (NRCSSD). Similar to the works of Maya et al. and Kim et al., $\mathrm{Li}$ and Teo [11] developed a model that is referred to as the network repair work scheduling and relief logistic problem (NRWSRLP). Multi-period bilevel programming problems were applied in this model to minimize the total required time for delivering the relief materials in the lower level and maximize the accessibility of the road network in the upper level. Extending from the previous research, Li et al. [14] focused on integrated logistics support scheduling (LSS) with repair crew scheduling and routing problems (RCSRP) to accomplish post disaster road network repair (PDRNR). The developed model utilizes non-linear programming and an intertwined two-stage heuristic algorithm (ITSHA) to determine the repair crew scheduling.

A bilevel programming model for an emergency recovery problem of the transportation network was proposed by Chen et al. [36]. They developed an emergency relief supply scheduling framework that considers different degrees of relief priority and multiple relief distribution centers. This model adopted the Artificial Bee Colony (ABC) technique that combines bilevel programming with a soft time window problem caused by road network failure.

Under insufficient information conditions in large-scale natural disasters, Sheu [17] proposed a dynamic relief demand management model for emergency logistics operation using a fuzzy clustering-based model to group affected regions, combine with the Technique for Order Preference by Similarity to Ideal Solution (TOPSIS) to identify the urgent relief demand associated with each group. Lu et al. [37] developed a model to minimize the total time of delivery relief logistics by deploying a rolling horizon approach with real-time information. Sheu and Pan [38] established a method for designing a centralized emergency supply network that supports emergency logistic operations considering the psychological cost. Furthermore, Sheu and Pan [29] proposed an optimization model to minimize the impact of disproportionate relief supply-demand on the affected region during the response phase using stochastic dynamic programming.

Zhang et al. [39] solved a dynamic job shop problem by adopting bridge-road transportation network restoration schedules. A genetic algorithm (GA) job shop problem was formulated to search the minimum recovery time and optimize the recovery trajectory of the whole bridge-road network. Another similar research performed by Li et al. [40] aimed to solve the optimization problem of the transportation network recovery strategy (TNRS) based on the emergency recovery phase (ERP). This optimization problem was solved by constructing a resilience-based bilevel model to obtain the optimal repair time sequence of the road segments.

The common assumption of repair resources that includes repair workers and equipment are characterized as work crews [41]. Taking advantage of the RCPSP definition, the proposed model treated repair resources as individual resources rather than the whole work crew, where the option of flexible resource assignment can be further considered. The type of resource in RCPSP activity can be divided into two categories: (1) renewable resources which can be used repeatedly by required activities (e.g., workers and equipment), and (2) non-renewable resources which are consumable with availability restrictions over the project period from the beginning to the end of the project (e.g., construction materials and 
repair project budget) [42,43]. Only renewable resources are considered in the proposed RCPSP-oriented model.

The main objective of RCPSP aims to minimize the total duration of the project schedule that consists of a set of activities linked by precedence constraints and restricted by multiple resource limitations [44-47]. Several studies have proved that RCPSP is able to solve complex scheduling problems for achieving project management goals, under the circumstances of dealing with complicated resource allocation and assignment issues. Alcaraz and Maroto [48] proposed a genetic algorithm-based model in a single-mode RCPSP environment to obtain the minimum project duration. Rahman et al. [49] considered three different areas - the construction industry, information technology, and healthcare system - to validate the effectiveness of the proposed GA-based RCPSP model. Several studies utilized mixed-integer linear programming optimization models to solve RCPSP. Pinto et al. [50] developed a model for an extension of the RCPSP problem, called the multi-mode resource-collaboration and constrained scheduling problem (MRCCSP), for the semiconductor industry. Chakrabortty et al. [51] developed a stochastic resourceconstrained project scheduling problem (SRCPSP) which minimizes the makespan of a project with stochastic activity durations. A constrained logic programming (CLP) technique was applied with a branch-and-cut algorithm to solve the SRCPSP model. Besides the mixed-integer linear programming (MILP) and CLP techniques, constraint programming (CP) techniques were utilized for resource-constrained multi-project scheduling problems with alternative activity chains and time flexibility (RCMPSP-ACTF) by Hauder et al. [52].

From the past research we discussed above, only a few research studies discussed emergency repair issues for the road network. Moreover, we found that no studies can provide an integrated scheduling solution with a rescheduling feature to consider the first-wave and second-wave disaster damages at the same time, and apply RCPSP concepts to solve the emergency repair scheduling problem for the road network. Therefore, this research is then conducted with such motivations.

\section{Methodology}

3.1. Model Concept

This study takes into account the resources required for repair activity at each disaster point and the limited equipment resources available to each maintenance unit. It assists decision makers to solve the problem of repair activity sequencing and resource allocation for all damaged road sections within the unit's area of responsibility. An RCPSP perspective is adopted to make an applicable repair plan of damaged road sections. In addition, the proposed model can also allocate resources to each disaster point in different combinations of types and quantities, according to the upper limit of the number of equipment resources that can be accommodated, and the changes in such combinations of resources corresponding to the different repair durations.

Although the schedule for the initial stage of the disaster confirms that the maintenance units are responsible for repairing all damaged disaster points within the region, there is still a high probability that new disaster points will be created after the first-wave disaster. Therefore, this research model takes actual post disaster scenarios into consideration and uses a rescheduling feature to reintegrate the schedule, so that the repair activities can be updated immediately after the status quo of any new damages has been properly evaluated by decision makers. The conceptual diagram of the proposed model is shown in Figure 1. 


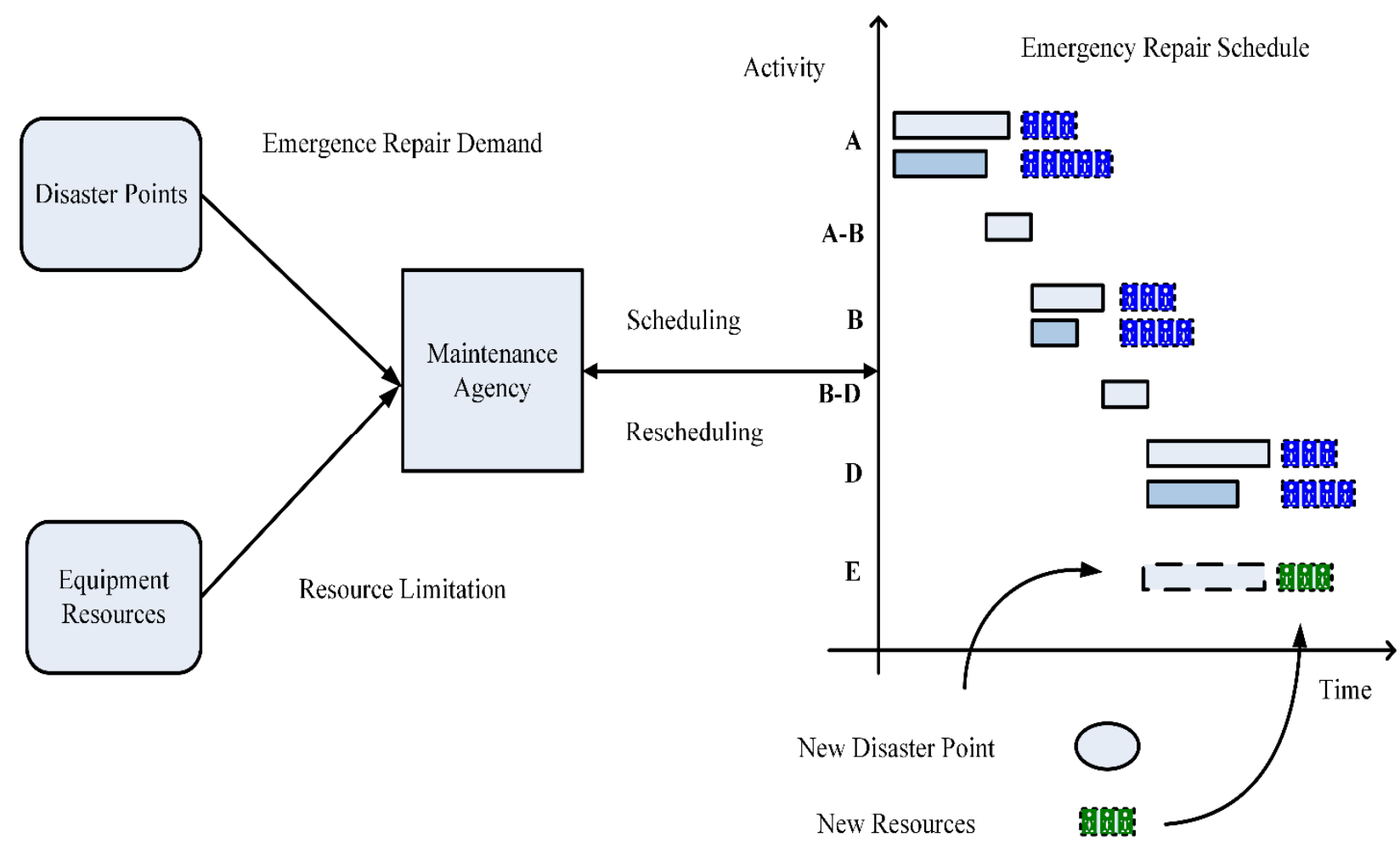

Figure 1. Conceptual diagram of emergency repair scheduling model.

\subsection{Model Description and Assumptions}

In this study, complying with the rules of the RCPSP framework, the following assumptions are made to appropriately simplify the complexity of the emergency repair scheduling problem, in order to smoothly carry out overall model development and reasonably preserve the problem characteristics:

(1) The emergency repair scheduling problem in this study defines damaged road sections as repair activities, and the traveling routes of equipment resources between resource and disaster points as transit activities; thus, the equipment resources required for each repair activity are dispatched through transit activities.

(2) Since the damage caused by a major natural disaster can be widely distributed, this study assumes that the decision maker of a maintenance unit, when planning emergency repair works for road sections, will appropriately delineate the scope of repair works within the unit's area of responsibility based on the location of its equipment resources and the location of each damaged road section.

(3) The disaster information usually includes the geographical location of the disaster point, the volume of disaster treatment, the type of equipment resources required for recovery, and the maximum resource capacity of the disaster point at the same time due to space limitations. The repair activity defined in this study is excavation work for rockfall and debris slides at the disaster point. It assumes that all the necessary parameters for emergency repair scheduling have been collected through proper sources.

(4) After a disaster, the main routes of a road network are prioritized by disaster-related vehicles, so this study assumes that the travel time of equipment resources traveling to the damaged road sections is known and the shortest, and is not affected by traffic flow or other factors. It is assumed that equipment resources, such as excavators and bulldozers, are transported to the disaster points by trailers. The major equipment resources considered here are excavators and bulldozers, which are the controlling resources of construction productivity for the problem domain of road network repair; 
other resources, such as workers and dump trucks, are assumed to be able to be provided upon request.

(5) In this study, it is assumed that the disaster points are completely blocked and impassable until the repair work is completed, but in order to meet the actual demand for disaster relief, the repair work of each disaster point is assumed to be performed in such a way that vehicles can pass. The movement of equipment resources occurs only in the following two situations: (1) from the location where the resources are located to the disaster location; and (2) after the completion of repair activity at one disaster location, to another disaster location to perform repairs.

(6) Once a repair activity for a disaster point begins, the resources cannot leave the disaster point or go to another disaster point for support, and repair activities cannot accept other resources to join the in-process repair work. Due to the emergency nature of the repair activity, it is assumed that all repair activities and transit activities are not allowed to be interrupted.

\subsection{Model Formulation}

To summarize the basic assumptions of the model in the previous subsection, this subsection introduces the mathematical equations of the proposed model, and the definition of model parameters and variables are shown in Table 1. IBM ILOG CPLEX Optimizer software and the constraint programming $(\mathrm{CP})$ approach are adopted for model development [53].

- Objective function

$$
\text { Minimize T }
$$

- Constraints

\subsection{Project Duration Calculation}

(1) Total project duration of all emergency repair activities.

The objective function is to minimize repair project total duration, shown as Equation (1). Equation (2) indicates that the total duration of the project is the end of the repair work at the last completed disaster point in the emergency repair project.

$$
T=\operatorname{Max}\left\{F_{i}\right\}, \forall i \in S I
$$

(2) Finish time of repair activity.

Equation (3) indicates that the finish time of repair activity at the disaster point is the sum of activity start time and selected activity duration.

$$
F_{u}=S_{u}+d_{u}, d_{u} \in D_{u}, \forall u \in S U
$$

(3) Finish time of transit activity.

Finish time of transit activity is the sum of activity start time and transit activity duration. Transit activities can be divided into two categories: the first group- the ones traveling from the resource point to the disaster point; the second group - the ones traveling from the preceding disaster point to the succeeding disaster point. Therefore, the restrictions for each category are made separately as Equations (4) and (5).

$$
\begin{gathered}
F_{n j}=S_{n j}+L T_{n j}, \forall n \in S N, \forall j \in S J, L T_{n j} \in D_{n j} \\
F_{i j}=S_{i j}+L T_{i j}, \forall i \in S I, \forall j \in S J, L T_{i j} \in D_{i j}
\end{gathered}
$$

(4) Transit activity execution.

If a specific transit activity is selected for resource dispatching, the number of equipment resources is greater than zero (i.e., this transit activity is really in execution status), then the duration of this transit activity is equal to the corresponding duration 
$l t_{n j} / l t_{i j}$; otherwise, it is not executed and its corresponding duration should be equal to zero, where such logical expression is shown as Equations (6) and (7) separately for two categories of transit activities.

$$
\begin{aligned}
& \text { If } L R_{n j}^{k}>0, \text { then } L T_{n j}=\text { lt } t_{n j} \text { If } L R_{n j}^{k}=0, \text { then } L T_{n j}=0 \forall n \in S N, \forall j \in S J, \forall k \in S K \\
& \text { If } L R_{i j}^{k}>0, \text { then } L T_{i j}=\text { lt } t_{i j} \text { If } L R_{i j}^{k}=0, \text { then } L T_{i j}=0 \forall i \in S I, \forall j \in S J, \forall k \in S K
\end{aligned}
$$

\begin{tabular}{|c|c|}
\hline Parameter & Statement \\
\hline$d_{u}$ & Duration of repair activity $u$ at disaster point $u$ \\
\hline$l t_{n j}$ & Duration of transit activity $n j$ from resource point $n$ to succeeding disaster point $j$ \\
\hline$l t_{i j}$ & Duration of transit activity $i j$ from preceding disaster point $i$ to succeeding disaster point $j$ \\
\hline$l f_{i}$ & Latest finish time of repair activity $i$ at disaster point \\
\hline$r_{n}^{k}$ & Resource supply quantity of resource type $k$ at resource point $n$ \\
\hline$r_{s n}^{k}$ & Resource supply quantity of resource type $k$ at resource point $n$ for responsibility area $s$ \\
\hline$r l_{i}^{k}$ & Maximum resource quantity that resource type $k$ can be accommodated at disaster site $i$ \\
\hline Variable & Statement \\
\hline$T$ & Total project duration \\
\hline$T_{S}$ & Total duration of responsibility area $s$ \\
\hline$S_{u}$ & Start time of repair activity $u$ \\
\hline$F_{u}$ & Finish time of repair activity $u$ \\
\hline$S_{i}$ & Start time of preceding repair activity $i$ \\
\hline$F_{i}$ & Finish time of preceding repair activity $i$ \\
\hline$F_{s i}$ & Finish time of preceding repair activity $i$ at responsibility area $s$ \\
\hline$S_{j}$ & Start time of succeeding repair activity $j$ \\
\hline$S_{n j}$ & Start time of transit activity $n j$ from resource point $n$ to succeeding disaster point $j$ \\
\hline$F_{n j}$ & Finish time of transit activity $n j$ from resource point $n$ to succeeding disaster point $j$ \\
\hline$S_{i j}$ & Start time of transit activity $i j$ from preceding disaster point $i$ to succeeding disaster point $j$ \\
\hline$F_{i j}$ & Finish time of transit activity $i j$ from preceding disaster point $i$ to succeeding disaster point $j$ \\
\hline$R_{i}^{k}$ & Resource usage of resource type $k$ of preceding repair activity $i$ \\
\hline$R_{s i}^{k}$ & Resource usage of resource type $k$ of preceding repair activity $i$ at responsibility area $s$ \\
\hline$R_{j}^{k l}$ & Resource usage of resource type $k$ of succeeding repair activity $i$ \\
\hline$R N_{i}^{k}$ & Remaining resource quantity after resource type $k$ deployment for repair activity $i$ \\
\hline$L R_{n j}^{k}$ & $\begin{array}{l}\text { Resource quantity of resource type } k \text { dispatched through transit activity } n j \text { from resource point } n \text { to succeeding } \\
\text { disaster point } j\end{array}$ \\
\hline$L R_{i j}^{k}$ & $\begin{array}{l}\text { Resource quantity of resource type } k \text { dispatched through transit activity } i j \text { from preceding disaster point } i \text { to } \\
\text { succeeding disaster point } j\end{array}$ \\
\hline$L T_{n j}$ & Duration of transit activity $n j$ from resource point $n$ to succeeding disaster point $j$ \\
\hline$L T_{i j}$ & Duration of transit activity $i j$ from preceding disaster point $i$ to succeeding disaster point $j$ \\
\hline Set & Statement \\
\hline$S$ & Set of emergency repair projects \\
\hline$S S_{f}$ & Set of responsibility areas, where $f=1,2,3, \ldots, g$ \\
\hline$S N$ & Set of resource points \\
\hline$S U$ & Set of recovery activities \\
\hline$S I$ & Set of preceding repair activities \\
\hline SJ & Set of succeeding repair activities \\
\hline SK & Set of resource types \\
\hline$S E_{t}$ & Set of in-progress repair activities at time interval $t$, where $t=1,2,3, \ldots, T$ \\
\hline$D_{u}$ & Set of the corresponding durations to different resource combinations for repair activity $u$ \\
\hline$D_{n j}$ & Set of durations of transit activity $n j$ from resource point $n$ to succeeding disaster point $j$ \\
\hline$D_{i j}$ & Set of durations of transit activity $i j$ from preceding disaster point $i$ to succeeding disaster point $j$ \\
\hline
\end{tabular}

Table 1. Parameters and variables of the proposed model. 


\subsection{Activity Precedence Relationship}

(1) Relationship among repair activities.

This study investigates the emergency repair issue from a scheduling perspective. Since the emergency repair work is quite urgent, this model assumes that all emergency repair works are completed at the disaster point and equipment resources are then immediately transported to the next disaster point through the connecting transit activity, and emergency repair work at the succeeding disaster point starts immediately after the arrival of the resources, which is the FS (finish-start) relationship in the scheduling precedence relationships, shown as Equation (8).

$$
S_{j} \geq \operatorname{Max}\left\{F_{i}+L T_{i j}\right\}, \forall i \in S I, \forall j \in S J
$$

(2) Relationship between repair activity and transit activity.

Since resource transit can be further divided into two situations, such as transit from the resource point to the disaster point and transit from one disaster point to another disaster point, the relationship between transit activity and repair activity is showed as Equations (9) and (10), respectively.

$$
\begin{gathered}
S_{j} \geq F_{n j}, \forall n \in S N, \forall j \in S J \\
S_{j} \geq F_{i j}, \forall i \in S I, \forall j \in S J
\end{gathered}
$$

\subsection{Resource Limitation}

(1) Resource total quantity.

Due to the limited amount of equipment resources, the number of resources used in repair work for each disaster point must be within the upper limit of the available amount of all types of resources. Equation (11) describes such constraints.

$$
R_{i}^{k} \leq \sum_{n \in S N} r_{n}^{k}, \forall i \in S I, \forall k \in S K
$$

The total number of resources used for all repair activities in-progress must be within the resource limit of each resource type $k$ at unit time $t$. Equation (12) describes such constraints.

$$
\sum_{i \in S T_{t}} R_{i}^{k} \leq \sum_{n \in S N} r_{n}^{k}, \forall k \in S K, t=1,2,3, \ldots, T
$$

(2) Resource dispatching consistency.

Complying with the rule of meeting the maximum number of resource dispatching from the resource point (or the preceding repair activity) to the succeeding repair activity equipment resources, the number of dispatching resources for all transit activities must be within the maximum number of resources of each resource type $k$, which is shown as Equations (13) and (14), respectively.

$$
\begin{aligned}
& r_{n}^{k} \geq \sum_{j \in S J} L R_{n j}^{k}, \forall n \in S N, \forall k \in S K \\
& R_{i}^{k} \geq \sum_{j \in S J} L R_{i j}^{k}, \forall i \in S I, \forall k \in S K
\end{aligned}
$$

In order to further confirm the quantity of equipment resources dispatched for repair activities, the sum of the resource amount dispatched and remaining after the dispatch should be equal to the amount as before the dispatch, which is shown as Equation (15).

$$
R_{i}^{k}=R N_{i}^{k}+\sum_{j \in S J} L R_{i j}^{k}, \forall i \in S I, \forall k \in S K
$$


(3) Resource receiving consistency.

Equipment resources are dispatched from preceding repair activities or resource points. Therefore, the quantity of resources received by any repair activity must be equal to the sum of resource quantity transited from the preceding disaster points or resource points, which is shown as Equation (16).

$$
R_{i}^{k}=\sum_{j \in S J} L R_{i j}^{k}+\sum_{n \in N} L R_{n j}^{k}, \forall j \in S J, \forall k \in S K
$$

(4) Resource limitation due to specific restrictions of different disaster points.

Each damaged road section has the maximum number of resources that can be accommodated at the same time during the execution of its own repair activity, due to site or terrain restrictions, so the number of resources at each disaster point must be constrained by the defined upper limit, shown as Equation (17).

$$
R_{i}^{k} \leq r l_{i}^{k}, \forall i \in S I, \forall k \in S K
$$

\subsection{Constraints for Special Restrictions}

To meet the special restrictions subjected to different emergency situations, the following constraints are considered as needed.

(1) Specify the latest start time of repair activity $i$.

$$
S_{i} \leq l s_{i}
$$

(2) Specify the latest finish time of repair activity $i$.

$$
F_{i} \leq l f_{i}
$$

(3) Responsibility area.

Once the status quo of all repair works is confirmed, the decision maker may divide the scope of all repair works into several responsibility areas for different maintenance units/resource points, as the subsets shown in Equation (20).

$$
S=S S_{1} \cup S S_{2} \cup S S_{3} \cup \ldots \cup S S_{g}
$$

The total duration of a repair project is controlled by the largest duration of all activities in each area of responsibility, shown as Equation (21). Equation (22) shows that the total duration of each subproject by responsibility area is the finish time of the last completed repair activity for all disaster points within each area.

$$
\begin{gathered}
T=\operatorname{Max}\left\{T_{s}\right\}, \forall s \in S S_{f}, f=1,2,3, \ldots, g \\
T_{s}=\operatorname{Max}\left\{F_{s i}\right\}, \forall s \in S S_{f}, \forall i \in S I, f=1,2,3, \ldots, g
\end{gathered}
$$

The total amount for each resource type $k$ at responsibility area $s$ must be within the maximum number of resources for all responsibility areas, shown as Equation (23). The number of resources used to perform repair work at each disaster site in each area of responsibility must also be within the maximum number of resources for each resource type in that area of responsibility, shown as Equation (24).

$$
\begin{gathered}
\sum_{s \in S S_{f}} r_{s n}^{k} \leq r_{n}^{k} \forall n \in S N, \forall k \in S K, f=1,2,3, \ldots, g \\
R_{s i}^{k} \leq \sum_{n \in S N} r_{s n}^{k}, \forall s \in S S_{f}, \forall i \in S I, \forall k \in S K, f=1,2,3, \ldots, g
\end{gathered}
$$




\section{Case Analysis and Discussion}

To verify the applicability of the proposed model, this section presents two sets of post disaster emergency repair cases for the road network to discuss the optimized results of this model using four different scenarios.

\subsection{Responsibility Area}

The current practices in Taiwanese public sectors on emergency repair scheduling issues are based on the concept of responsibility area. The lines of responsibility in Figure 2 are used to delineate the emergency repair areas of different maintenance units. Case 1, dividing into three responsibility areas, and including three resource points and fifteen disaster points, is presented in Figure 2 to validate the proposed model and further analyze the optimized results.

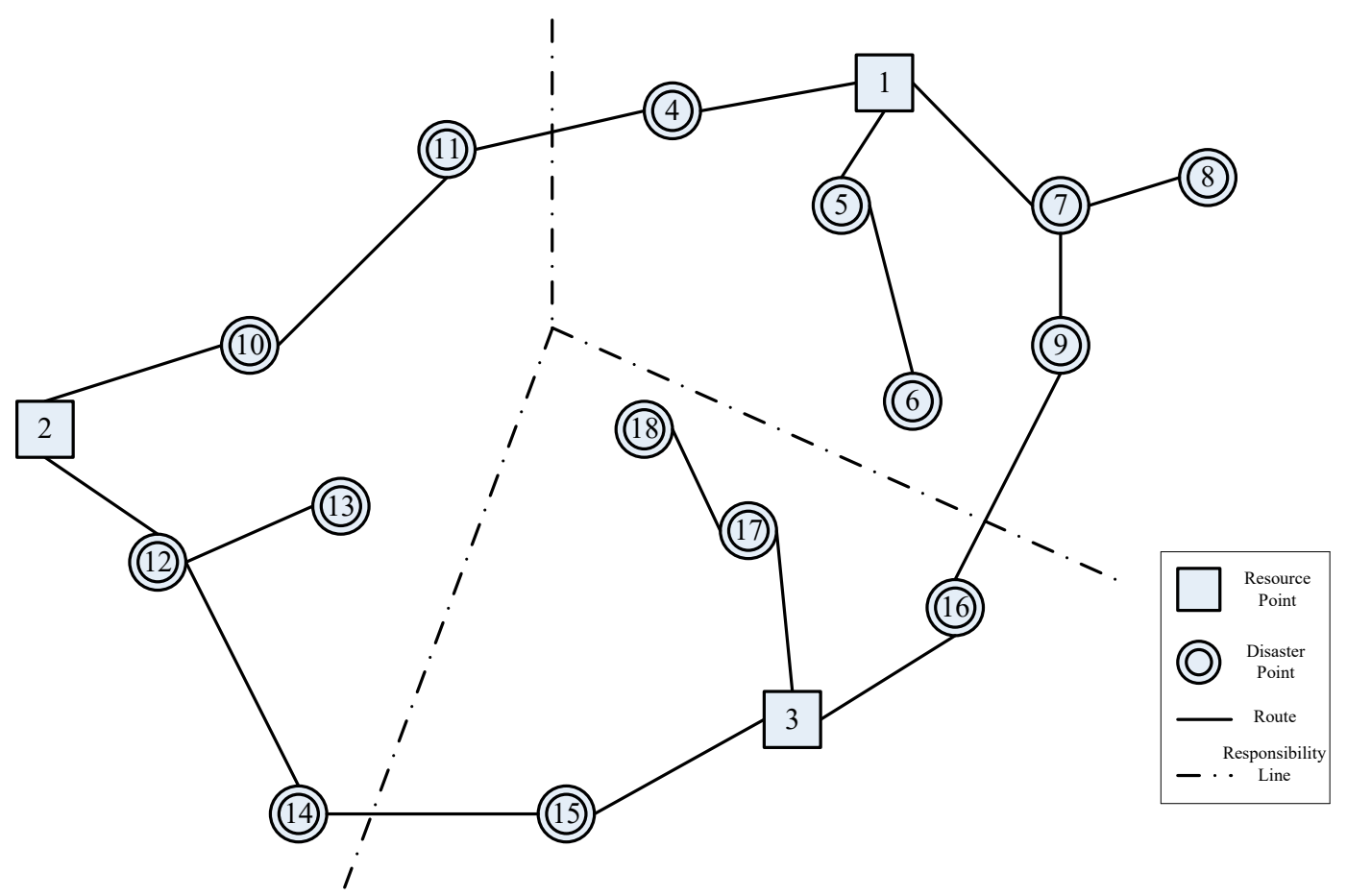

Figure 2. Diagram of the responsibility areas of Case 1.

In Case 1, the equipment resources in this study are excavators and bulldozers, with $\mathrm{R} 1$ resource representing the excavators and $\mathrm{R} 2$ resource representing the bulldozers; their corresponding quantities at different resource points are shown in Table 2. Detailed information of the combinations of equipment resources required for each disaster point and the corresponding repair durations for each combination of resources is shown on Table 3.

Table 2. Resource types and quantity (Case 1).

\begin{tabular}{ccc}
\hline Resource Point No. & R1 Quantity & R2 Quantity \\
\hline 1 & 6 & 6 \\
2 & 3 & 3 \\
3 & 5 & 4 \\
\hline
\end{tabular}


Table 3. Resources required for disaster point and corresponding repair durations (Case 1).

\begin{tabular}{|c|c|c|c|}
\hline Disaster Point No. & $\begin{array}{c}\text { R1 Required } \\
\text { Quantity }\end{array}$ & $\begin{array}{l}\text { R2 Required } \\
\text { Quantity }\end{array}$ & $\begin{array}{l}\text { Repair Duration } \\
\text { (in } 20 \mathrm{~min} \text { ) }\end{array}$ \\
\hline 4 & 1 & 1 & 30 \\
\hline \multirow{2}{*}{5} & 3 & 3 & 45 \\
\hline & 3 & 2 & 53 \\
\hline \multirow[b]{2}{*}{6} & 4 & 3 & 18 \\
\hline & 3 & 3 & 23 \\
\hline \multirow[b]{2}{*}{7} & 2 & 2 & 72 \\
\hline & 2 & 1 & 85 \\
\hline \multirow{2}{*}{8} & 2 & 1 & 19 \\
\hline & 1 & 1 & 24 \\
\hline 9 & 1 & 1 & 53 \\
\hline \multirow{2}{*}{10} & 2 & 1 & 60 \\
\hline & 1 & 1 & 72 \\
\hline 11 & 1 & 1 & 15 \\
\hline \multirow{2}{*}{12} & 2 & 2 & 31 \\
\hline & 1 & 1 & 52 \\
\hline \multirow{2}{*}{13} & 2 & 2 & 17 \\
\hline & 1 & 1 & 29 \\
\hline \multirow{2}{*}{14} & 2 & 1 & 12 \\
\hline & 1 & 1 & 17 \\
\hline 15 & 1 & 1 & 12 \\
\hline \multirow[b]{2}{*}{16} & 2 & 1 & 30 \\
\hline & 1 & 1 & 35 \\
\hline \multirow[b]{2}{*}{17} & 3 & 2 & 90 \\
\hline & 2 & 2 & 103 \\
\hline \multirow{2}{*}{18} & 2 & 2 & 54 \\
\hline & 1 & 1 & 92 \\
\hline
\end{tabular}

The possible route is defined as a two-way traffic path, and if we take repair activity at 14 and 15 in Case 1 as an example, the transit activity between these two disaster points can be divided into (1) transit from disaster point 14 to disaster point 15 and (2) transit from disaster point 15 to disaster point 14.

The definition of a repair activity in the RCPSP framework is that the repair activity always exists in a repair project, as it must be fully completed as part of a repair project. However, a transit activity exists in a repair project only when equipment resources are being transited to a disaster point via this route, otherwise it is only a possible route, and if it is not selected for resource transit, then such transit activity does not exist in the RCPSP environment, during solution seeking runtime. Information of each resource transit route, including departing location, arrival location, and route travel time, is shown in Table 4.

From the optimized results of the proposed model, the whole emergency repair process is shown in Figure 3 and the scheduling results are shown in Table 5. The minimum total duration of this repair project in Case 1 is 147 (unit: $20 \mathrm{~min}$ ).

To summarize, new disaster points and new resources will definitely affect the original repair schedule, so the proposed model must integrate the feature of rescheduling. Accordingly, this study applies a rescheduling feature so that the model can reschedule all repair works after the occurrence of a new disaster or the addition of new resources.

In order to verify that the proposed model can take into account the addition of new disaster and resource points, Case 2 is presented for further analysis. Case 2 analysis is divided into three parts, with the following scenarios: (1) the initial phase of the disaster, including one resource point and six disaster points; (2) a subsequent disaster occurs at 
unit time 12, resulting in three new disaster points occurring, at which time the status quo of this repair project increases to nine disaster sites, from the original six disaster points; (3) at unit time 32, after confirming the completion of all emergency repair works in the unit's area of responsibility, the neighboring maintenance unit dispatched their available resources to support this repair project, and at this time, there are two resource points and nine disaster points. We will discuss these scenarios in three subsections as follows.

Table 4. Resource transit route and travel time (Case 1).

\begin{tabular}{|c|c|c|c|}
\hline Resource Transit Route & Departing Location & Arrival Location & $\begin{array}{l}\text { Travel Time } \\
\text { (20 min })\end{array}$ \\
\hline 1 & 1 & 4 & 2 \\
\hline 2 & 1 & 5 & 1 \\
\hline 3 & 1 & 7 & 3 \\
\hline 4 & 2 & 10 & 2 \\
\hline 5 & 2 & 12 & 2 \\
\hline 6 & 3 & 15 & 5 \\
\hline 7 & 3 & 16 & 2 \\
\hline 8 & 3 & 17 & 2 \\
\hline 9 & 4 & 1 & 2 \\
\hline 10 & 5 & 1 & 1 \\
\hline 11 & 5 & 6 & 4 \\
\hline 12 & 6 & 5 & 4 \\
\hline 13 & 7 & 1 & 3 \\
\hline 14 & 7 & 8 & 2 \\
\hline 15 & 7 & 9 & 1 \\
\hline 16 & 8 & 7 & 2 \\
\hline 17 & 9 & 7 & 1 \\
\hline 18 & 10 & 2 & 2 \\
\hline 19 & 10 & 11 & 3 \\
\hline 20 & 11 & 10 & 3 \\
\hline 21 & 12 & 2 & 2 \\
\hline 22 & 12 & 13 & 2 \\
\hline 23 & 12 & 14 & 4 \\
\hline 24 & 13 & 12 & 2 \\
\hline 25 & 14 & 12 & 4 \\
\hline 26 & 15 & 3 & 5 \\
\hline 27 & 16 & 3 & 2 \\
\hline 28 & 17 & 3 & 2 \\
\hline 29 & 17 & 18 & 1 \\
\hline 30 & 18 & 17 & 1 \\
\hline
\end{tabular}

\subsubsection{The Initial Phase of the Disaster}

In order to make scenario comparison more obvious, only one single type of resource is considered in Case 2. The initial stage of Case 2 is illustrated in Figure 4, where the total number of resources that can be dispatched from resource point 1 is 7 . The number of resources required for each disaster point and the corresponding repair durations are shown in Table 6, and the departing location, arrival location, and travel time of each resource transit route are shown in Table 7. 


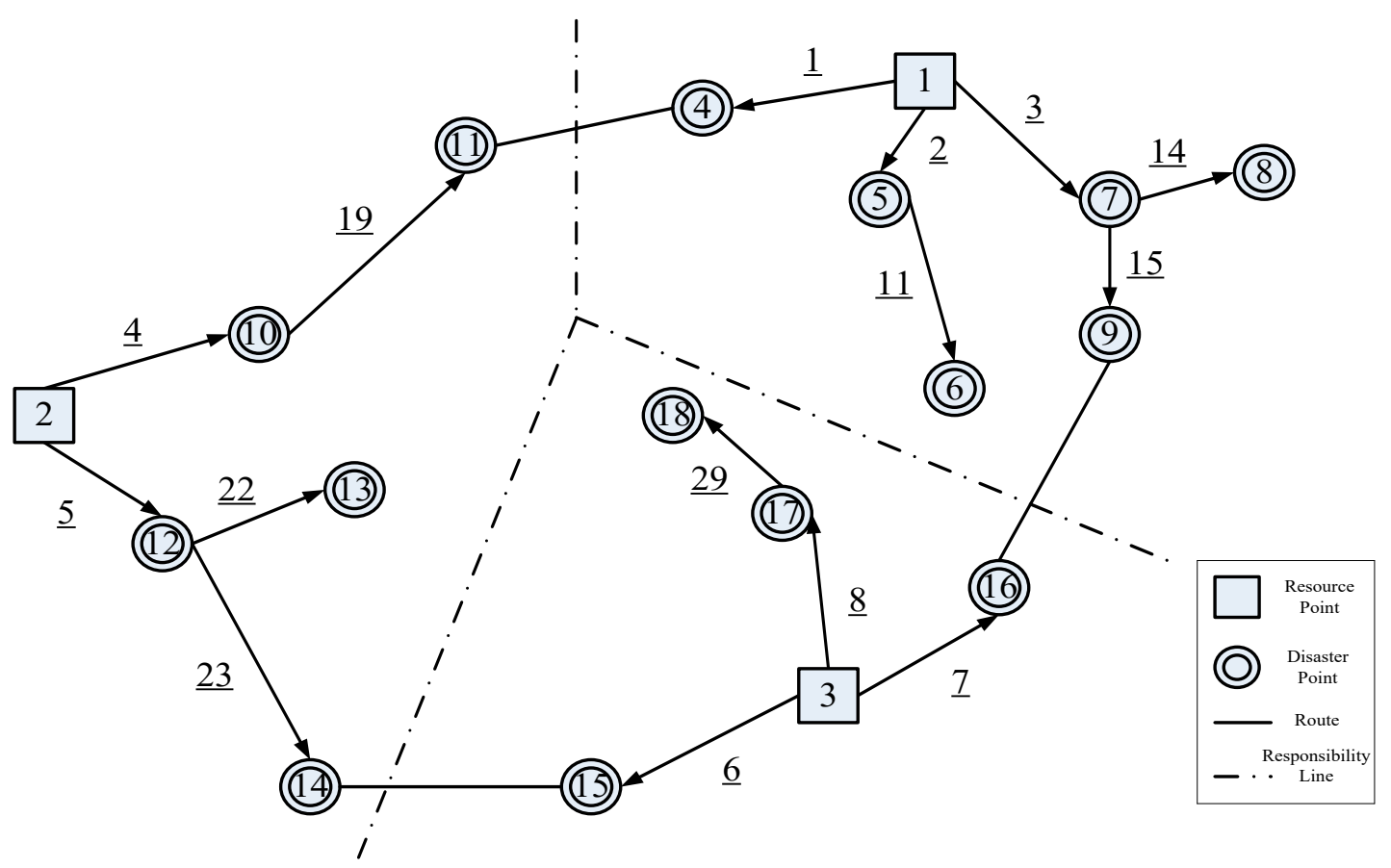

Figure 3. Diagram of emergency repair process based on responsibility area (Case 1).

Based on the optimized results of the proposed model, a schematic diagram of the emergency repair process at the initial stage of the disaster is shown in Figure 5, and the scheduling results are summarized in Table 8 , which shows that the minimum total duration of this repair project is 131 (unit: $20 \mathrm{~min}$ ).

Table 5. Scheduling result for Case 1.

\begin{tabular}{|c|c|c|c|c|c|c|}
\hline $\begin{array}{l}\text { Disaster } \\
\text { Point No. }\end{array}$ & $\begin{array}{c}\text { R1 } \\
\text { Usage }\end{array}$ & $\begin{array}{c}\text { R2 } \\
\text { Usage }\end{array}$ & $\begin{array}{l}\text { Repair Start Time } \\
\text { (20 min })\end{array}$ & $\begin{array}{l}\text { Repair Duration } \\
\text { (20 min) }\end{array}$ & $\begin{array}{l}\text { Repair finish Time } \\
\text { (20 min) }\end{array}$ & $\begin{array}{c}\text { Resource } \\
\text { Transit Route }\end{array}$ \\
\hline 4 & 1 & 1 & 2 & 30 & 32 & 1 \\
\hline 5 & 3 & 3 & 1 & 45 & 46 & 2 \\
\hline 6 & 3 & 3 & 50 & 23 & 73 & 11 \\
\hline 7 & 2 & 2 & 3 & 72 & 75 & 3 \\
\hline 8 & 1 & 1 & 77 & 24 & 101 & 14 \\
\hline 9 & 1 & 1 & 76 & 53 & 129 & 15 \\
\hline 10 & 1 & 1 & 2 & 72 & 74 & 4 \\
\hline 11 & 1 & 1 & 77 & 15 & 92 & 19 \\
\hline 12 & 2 & 2 & 2 & 31 & 33 & 5 \\
\hline 13 & 1 & 1 & 35 & 29 & 64 & 22 \\
\hline 14 & 1 & 1 & 37 & 17 & 54 & 23 \\
\hline 15 & 1 & 1 & 5 & 12 & 17 & 6 \\
\hline 16 & 1 & 1 & 2 & 35 & 37 & 7 \\
\hline 17 & 3 & 2 & 2 & 90 & 92 & 8 \\
\hline 18 & 2 & 2 & 93 & 54 & 147 & 29 \\
\hline
\end{tabular}




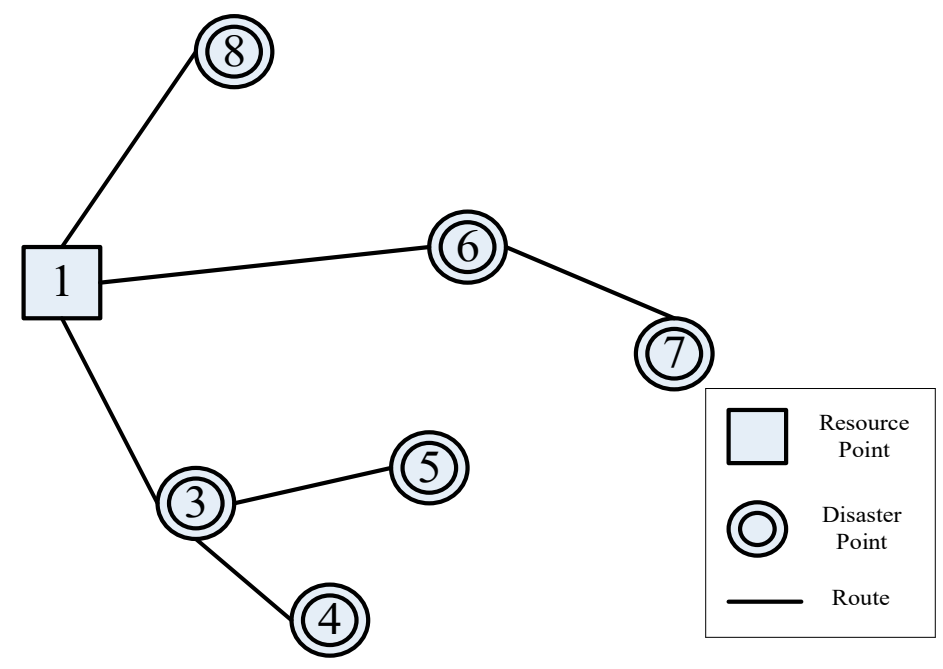

Figure 4. Diagram of initial stage of the disaster (Case 2).

Table 6. Resources required for the initial stage of a disaster and repair durations (Case 2).

\begin{tabular}{ccc}
\hline Disaster Point No. & Resource Required Quantity & Repair Duration (in 20 min) \\
\hline \multirow{2}{*}{3} & 3 & 40 \\
& 2 & 50 \\
\multirow{2}{*}{4} & 2 & 27 \\
& 1 & 46 \\
\hline \multirow{2}{*}{5} & 2 & 45 \\
& 1 & 76 \\
\hline \multirow{2}{*}{6} & 3 & 71 \\
& 2 & 85 \\
\hline \multirow{2}{*}{7} & 2 & 53 \\
& 1 & 90 \\
\hline
\end{tabular}

Table 7. Resource transit routes and travel times in the initial stage of a disaster (Case 2).

\begin{tabular}{cccc}
\hline Resource Transit Route & Departing Location & Arrival Location & $\begin{array}{c}\text { Travel Time } \\
\text { (20 min) }\end{array}$ \\
\hline 1 & 1 & 3 & 2 \\
2 & 1 & 6 & 4 \\
3 & 1 & 8 & 2 \\
4 & 3 & 1 & 2 \\
5 & 3 & 4 & 1 \\
6 & 3 & 5 & 2 \\
7 & 4 & 3 & 1 \\
8 & 5 & 3 & 2 \\
9 & 6 & 1 & 4 \\
10 & 6 & 7 & 3 \\
11 & 7 & 6 & 3 \\
12 & 8 & 1 & 2 \\
\hline
\end{tabular}




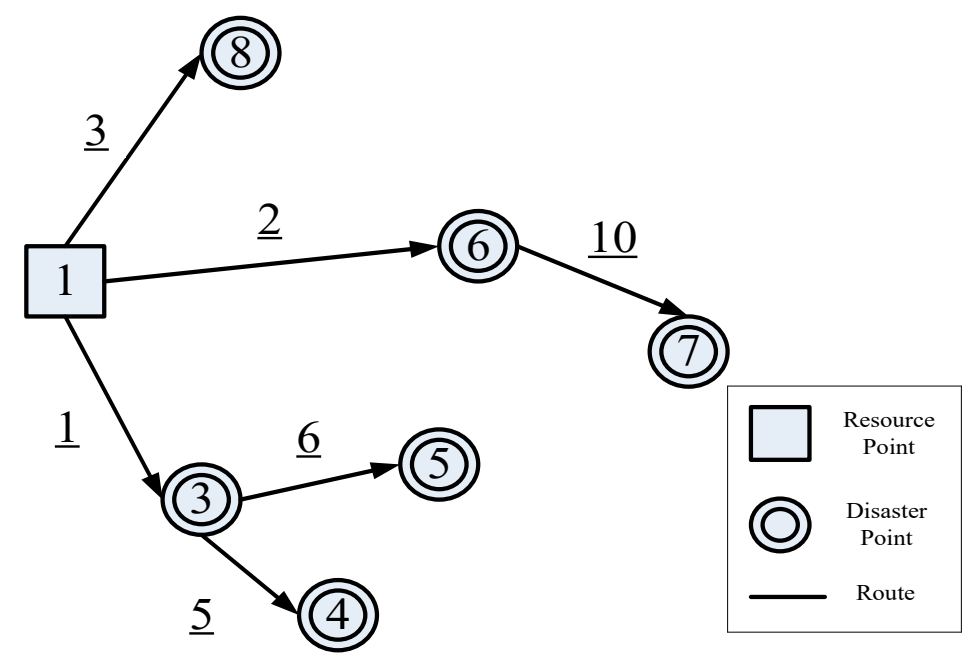

Figure 5. Diagram of emergency repair process at the initial stage of the disaster (Case 2).

Table 8. Scheduling results of the initial stage of the disaster (Case 2).

\begin{tabular}{cccccc}
\hline $\begin{array}{c}\text { Disaster } \\
\text { Point No. }\end{array}$ & $\begin{array}{c}\text { Resource } \\
\text { Usage }\end{array}$ & $\begin{array}{c}\text { Repair Start } \\
\text { Time } \\
\mathbf{( 2 0} \text { min) }\end{array}$ & $\begin{array}{c}\text { Repair } \\
\text { Duration } \\
\mathbf{( 2 0} \text { min) }\end{array}$ & $\begin{array}{c}\text { Repair } \\
\text { Finish Time } \\
\mathbf{( 2 0} \text { min) }\end{array}$ & $\begin{array}{c}\text { Resource } \\
\text { Transit } \\
\text { Route }\end{array}$ \\
\hline 3 & 3 & 2 & 40 & 42 & 1 \\
4 & 2 & 43 & 27 & 70 & 5 \\
5 & 1 & 44 & 76 & 120 & 6 \\
6 & 3 & 4 & 71 & 75 & 2 \\
7 & 2 & 78 & 53 & 131 & 10 \\
8 & 1 & 25 & 27 & 3 \\
\hline \multicolumn{7}{c}{ Repair project total duration: $131(20 \mathrm{~min})$} \\
\hline
\end{tabular}

\subsubsection{New Disaster Points}

However, at unit time 12 after the initial disaster occurs, three new disaster points (No. 9, 10, and 11) are added to the area due to the second-wave effects of a subsequent disaster, and the decision maker must immediately update the original repair schedule to include these new disaster points in the repair project, taking into account all disaster points in this area. A schematic diagram of new disaster points is shown in Figure 6.

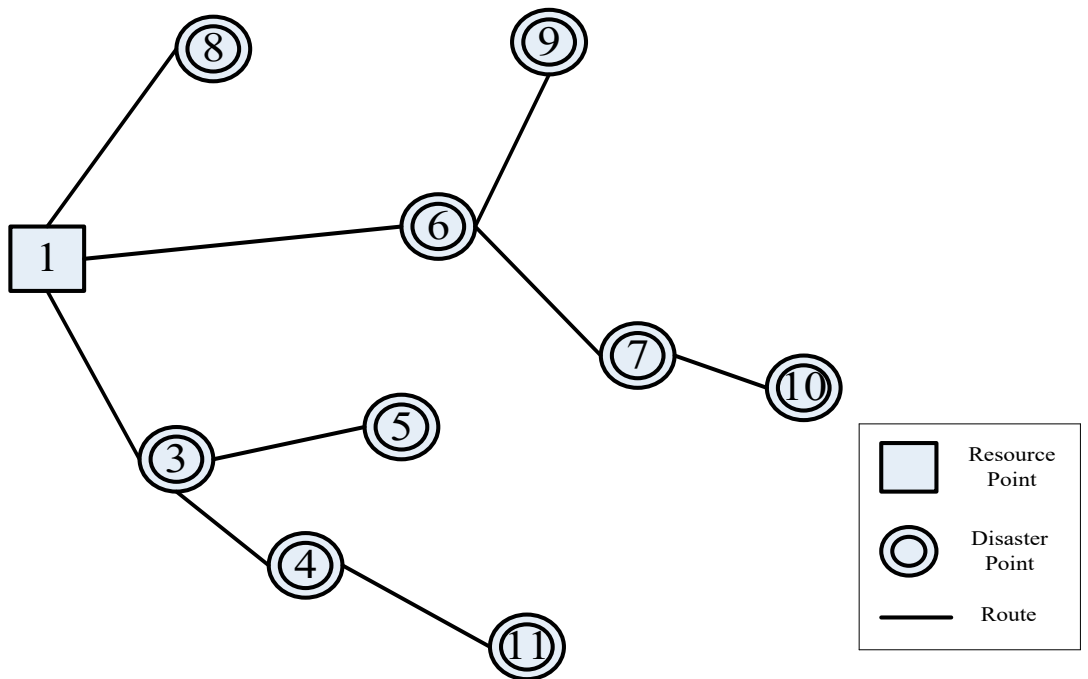

Figure 6. Diagram of new disaster points after it occurred. 
Except for the departing locations, arrival locations, and travel times of resource transit routes listed in Table 7 of Section 4.1.1 at the initial stage of the disaster, more information needs to be updated, such as the new routes for transporting resources to new disaster points (i.e., Figure 6, new routes from disaster points 6 to 9, disaster points 7 to 10, and disaster points 4 to 11); the related information is organized in Tables 9 and 10.

Table 9. Resource requirements and repair durations for new disaster points (Case 2).

\begin{tabular}{ccc}
\hline Disaster Point No. & Resource Required Quantity & Repair Duration (20 min) \\
\hline \multirow{2}{*}{9} & 2 & 27 \\
& 1 & 45 \\
\hline \multirow{2}{*}{10} & 3 & 8 \\
& 2 & 10 \\
\hline \multirow{2}{*}{11} & 3 & 10 \\
& 2 & 12 \\
\hline
\end{tabular}

Table 10. New resource transit routes and new travel times after new disaster points occur (Case 2).

\begin{tabular}{cccc}
\hline Resource Transit Route & Departing Location & Arrival Location & $\begin{array}{c}\text { Travel Time } \\
\text { (20 min) }\end{array}$ \\
\hline 13 & 4 & 11 & 2 \\
14 & 6 & 9 & 2 \\
15 & 7 & 10 & 1 \\
16 & 9 & 6 & 2 \\
17 & 10 & 7 & 1 \\
18 & 11 & 4 & 2 \\
\hline
\end{tabular}

Worth being noted, the purpose of rescheduling is to take new repair activities into account in the original schedule and to update the repair schedule by rescheduling all remaining repair activities, with a minimal change in planned schedule. However, in order to avoid unnecessary changes to the planned repair schedule at the initial stage of the disaster, this study restricts the optimized results of the original repair activities at the initial stage of the disaster (disaster points 3,4,5,6,7, and 8), in terms of resource allocation, repair duration, and transit activity selection, and does not allow any rescheduling on those as-planned solutions. Therefore, the following solutions are enforced into the model formulation as follows, in order to comply with the purpose of rescheduling, where the quantities of resources dispatched and the activity durations should stay at the values of the current optimal solution before rescheduling, denoted as the $\left(^{*}\right)$ sign, shown as Equation (25).

$$
T=t * \text {, then }\left\{R_{i}^{k}, L R_{n j}^{k}, L R_{i j}^{k}\right\}=\left\{r_{i}^{k} *, l r_{n j}^{k} *, l r_{i j}^{k} *\right\} \text {, and }\left\{d_{i}, L T_{n j}, L T_{i j}\right\}=\left\{d_{i} *, l t_{n j} *, l t_{i j} *\right\}
$$

Since three new disaster points occur after the initial disaster stage, the decision maker has to incorporate the new repair activities into the original repair project and update the schedule that had already been planned for the initial stage of the disaster. Figure 7 shows the updated repair process, and Table 11 lists detailed rescheduling results. From the results, it can be observed that the proposed model can integrate the original schedule with the occurrence of new disaster points, and search for the new optimal repair schedule with rescheduling effort. The minimum total duration of the new repair project is 142 (unit: $20 \mathrm{~min})$. 


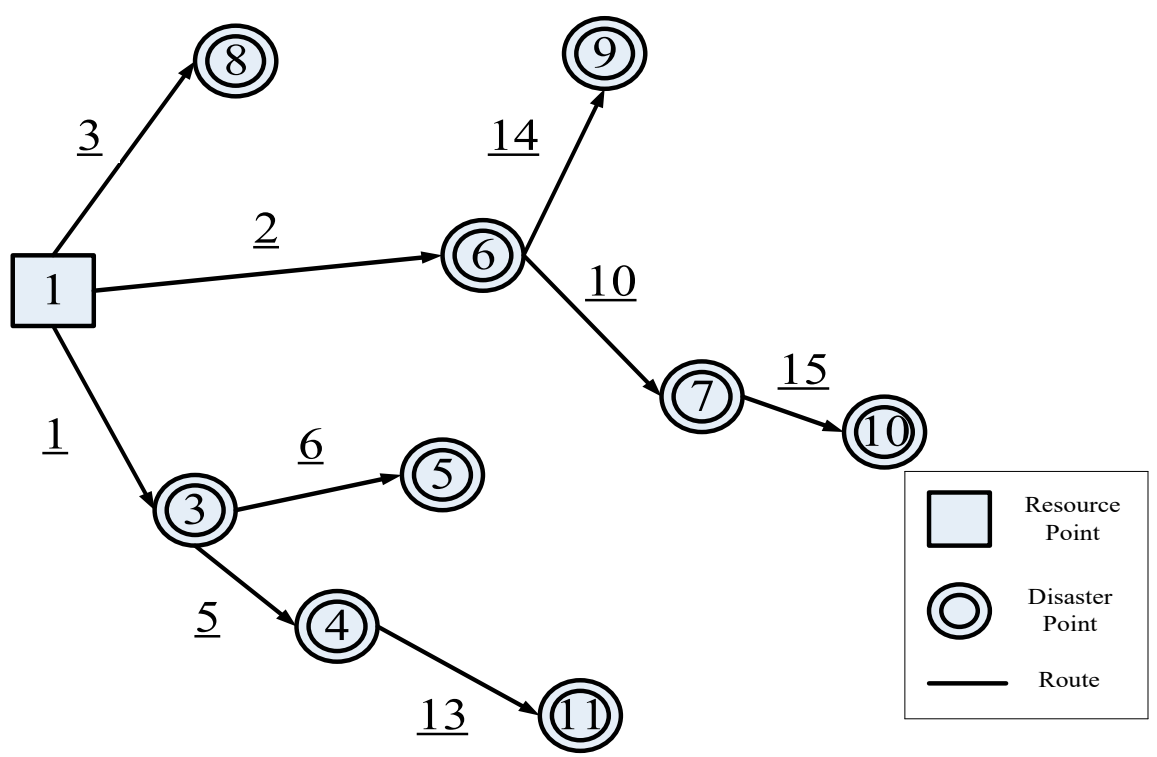

Figure 7. Diagram of the repair process after new disaster point occurs (Case 2).

Table 11. Rescheduling results after new disaster point occurs.

\begin{tabular}{cccccc}
\hline $\begin{array}{c}\text { Disaster } \\
\text { Point No. }\end{array}$ & $\begin{array}{c}\text { Resource } \\
\text { Usage }\end{array}$ & $\begin{array}{c}\text { Repair Start } \\
\text { Time } \\
(\mathbf{2 0} \text { min) }\end{array}$ & $\begin{array}{c}\text { Repair } \\
\text { Duration } \\
\mathbf{( 2 0} \text { min) }\end{array}$ & $\begin{array}{c}\text { Repair } \\
\text { Finish Time } \\
\mathbf{( 2 0} \text { min) }\end{array}$ & $\begin{array}{c}\text { Resource } \\
\text { Transit } \\
\text { Route }\end{array}$ \\
\hline 3 & 3 & 2 & 40 & 42 & 1 \\
4 & 2 & 43 & 27 & 70 & 5 \\
5 & 1 & 44 & 76 & 120 & 6 \\
6 & 3 & 4 & 71 & 75 & 2 \\
7 & 2 & 2 & 53 & 131 & 10 \\
8 & 1 & 25 & 27 & 3 \\
9 & 1 & 132 & 10 & 122 & 14 \\
10 & 2 & 72 & 12 & 84 & 13 \\
11 & 2 & \multicolumn{5}{c}{} \\
\hline
\end{tabular}

\subsubsection{New Resource Point}

At unit time 32 after the initial disaster, one neighboring maintenance unit has completed all repair works of the damaged road sections within its own area of responsibility. Under the command of superior authority, this neighboring maintenance unit dispatches their available resources to support this repair project. Since the neighboring engineering unit joins the repair project, the decision maker must confirm the number of new resources that can be cooperated and dispatched, and then update the repair schedule again to include the new resources in the emergency repair project schedule.

The new resource point is Resource Point 2, which has six new resources, as shown in Figure 8. For this new resource point, it is necessary to add more routes between the new resource point and the disaster point (i.e., Figure 8: new routes between resource point 2 and disaster point 9, resource point 2 and disaster 10, and resource point 2 and disaster 11), and the related information is summarized in Table 12. 


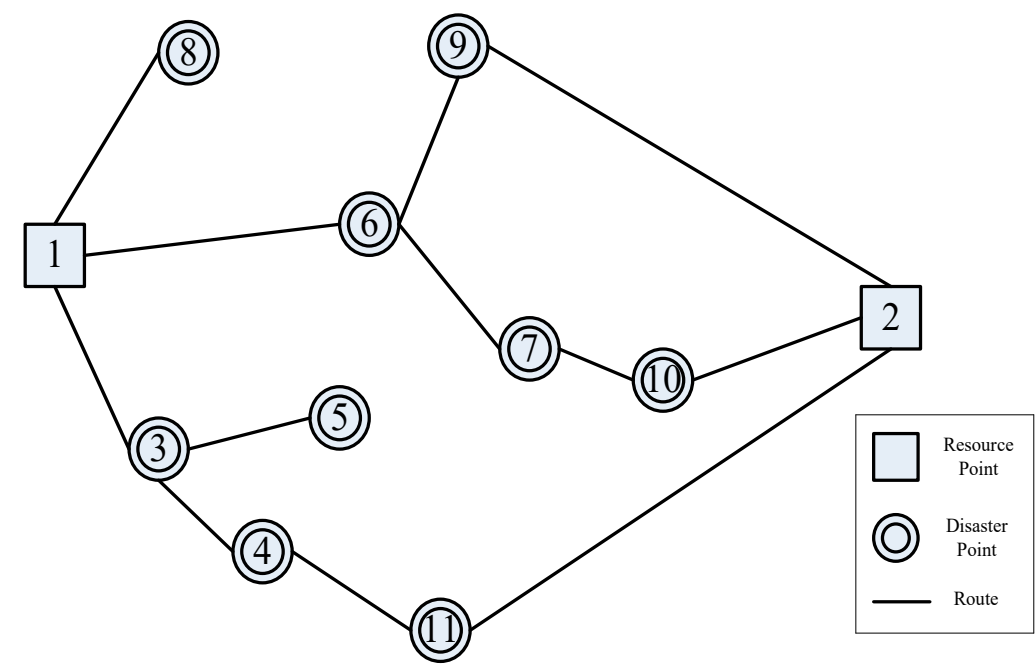

Figure 8. Schematic diagram after new resource point is added (Case 2).

Table 12. New resource transit routes and new travel times after new resource point is added (Case 2).

\begin{tabular}{cccc}
\hline Resource Transit Route & Departing Location & Arrival Location & $\begin{array}{c}\text { Travel Time } \\
\text { (20 min) }\end{array}$ \\
\hline 19 & 2 & 9 & 5 \\
20 & 2 & 10 & 4 \\
21 & 2 & 11 & 5 \\
22 & 9 & 2 & 5 \\
23 & 10 & 2 & 4 \\
24 & 11 & 2 & 5 \\
\hline
\end{tabular}

As discussed in previous Section 4.1.2, the optimized result has been updated to the first rescheduling result. The rescheduling feature allows the decision maker the permission to update the schedule result of the new disaster points (disaster points 9, 10, and 11) that occurred in unit time 12, and restrict initial disaster points $3,4,5,6,7$, and 8 without rescheduling actions since no or minimal change in the initial stage's schedule is expected.

A schematic diagram of the repair process after rescheduling the addition of new resources is shown in Figure 9, and the updated rescheduling results are shown in Table 13. From the optimized result, with the support of new resources, a minimum total project duration of 131 (unit: $20 \mathrm{~min}$ ) is an improvement, compared with the result of the previous scenario with the total duration of 142 (unit: $20 \mathrm{~min}$ ).

Table 13. Rescheduling results after new resource point is added (Case 2).

\begin{tabular}{cccccc}
\hline $\begin{array}{c}\text { Disaster } \\
\text { Point No. }\end{array}$ & $\begin{array}{c}\text { Resource } \\
\text { Usage }\end{array}$ & $\begin{array}{c}\text { Repair Start } \\
\text { Time } \\
(\mathbf{2 0} \text { min) }\end{array}$ & $\begin{array}{c}\text { Repair } \\
\text { Duration } \\
(\mathbf{2 0 m i n})\end{array}$ & $\begin{array}{c}\text { Repair } \\
\text { Finish Time } \\
\mathbf{( 2 0 m i n )}\end{array}$ & $\begin{array}{c}\text { Resource } \\
\text { Transit } \\
\text { Route }\end{array}$ \\
\hline 3 & 3 & 2 & 40 & 42 & 1 \\
4 & 2 & 43 & 27 & 70 & 5 \\
5 & 1 & 44 & 76 & 120 & 6 \\
6 & 3 & 4 & 71 & 75 & 2 \\
7 & 2 & 78 & 53 & 131 & 10 \\
8 & 1 & 2 & 25 & 27 & 3 \\
9 & 1 & 37 & 45 & 82 & 19 \\
10 & 2 & 36 & 10 & 46 & 20 \\
11 & 3 & 37 & 10 & 47 & 21 \\
\hline
\end{tabular}

Repair project total duration: $131(20 \mathrm{~min})$ 


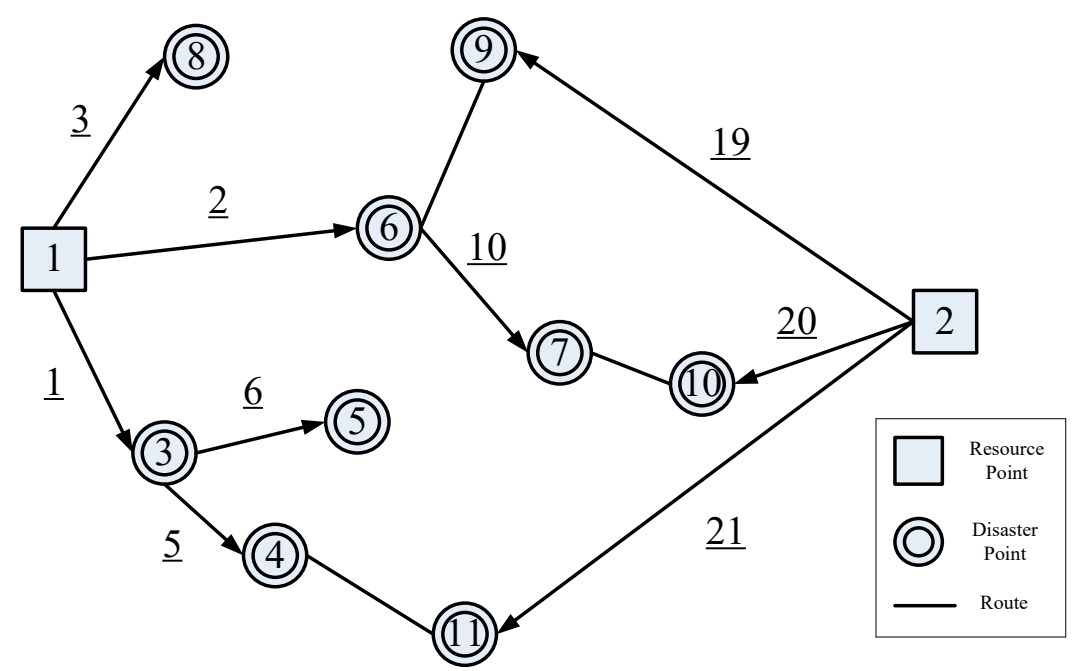

Figure 9. Diagram of the repair process after new resource point is added (Case 2).

As we compare the schedule before (Table 10) and after (Table 12) the new resources are added, we can see that disaster points 9, 10, and 11 are geographically closer to the new resources than the initial ones, so the repair schedules of these three disaster points are finished much earlier after the neighboring maintenance unit supports them, and the interesting discussions are presented as follows.

1. Disaster point 9: Due to the support of new resources, the rescheduling feature makes this repair activity schedule 40 time units earlier than the new resource site.

2. Disaster point 10: For the same reason as above, the emergency repair activity at this disaster point was scheduled 96 time units ahead of schedule.

3. Disaster point 11: Due to the full deployment of the resources at the new resource point, the resources allocated to disaster point 11 are increased from two to three, which allows the repair work to start earlier at unit time 37 and finish earlier at unit time 47 after rescheduling.

Summarizing the analysis in the above three subsections, the emergency repair scheduling model proposed in this study can take into account the possibility of new disasters and new resources and utilize the rescheduling feature to update the schedule after the occurrence of a new situation in response to different unexpected situations in the emergency repair project, with the principle of no change or changing the planned schedule at the minimum scale.

\section{Conclusions and Recommendations}

Major natural disasters in recent years have not only awakened people's awareness of disaster prevention, but have also highlighted the importance of the post disaster emergency repair problem. This study investigates resource allocation and the sequence of the emergency repair scheduling problem in post disaster recovery practice and develops a novel scheduling model to solve the emergency repair scheduling problem for the road network. In the resource allocation setting of the model, this study considers the type of repair resources, and each equipment resource is the basic unit of minimum resource allocation. Taking the benefits of flexible resource allocation in the RCPSP framework, it can be observed that the repair resources can be allocated in a more flexible way in the repair projects to accelerate recovery speed, compared with the traditional VRP approach adopted in previous studies. Moreover, this study introduces a rescheduling feature into the proposed scheduling model, so that it can be updated in response to unexpected changes of project contents (e.g., new disaster point and new supporting resource), with minimal or no change to the original schedule.

This research currently considers only excavators and bulldozers as equipment resources, and the resource combination and corresponding repair duration of each damaged 
road section are currently limited to two groups, but the model can actually consider the setting of multiple numbers. Therefore, for future work, other repair equipment can be considered in resource practices and increase the number of resource and duration combinations in order to expand the scale of the model. Additionally, in this study, the travel time of equipment resources as the duration of transit activity is set as a fixed value in the model and is not affected by traffic flow or other factors, but the actual post disaster conditions may change due to road accidents or peak hours. More assessment of the travel time parameter should be conducted for further investigation. Moreover, a future research direction could consider building a post disaster emergency scheduling system that provides (1) an interface for inputting repair project information and (2) an interface for outputting emergency scheduling results and related diagrams and tables. Users can directly input information about the location and workload of each disaster point, the resources required for repair activities, the types and quantities of resources to which each maintenance unit can devote for repair works, and the transit routes of equipment resources.

Author Contributions: Conceptualization, S.-S.L., W.T.C.; formal analysis, S.-S.L., Y.-H.H. and M.F.A.A.; investigation, S.-S.L.; writing-original draft preparation, S.-S.L. and M.F.A.A.; writing-review and editing, S.-S.L. and M.F.A.A.; supervision, S.-S.L. All authors have read and agreed to the published version of the manuscript.

Funding: This research received no external funding.

Institutional Review Board Statement: Not applicable.

Informed Consent Statement: Not applicable.

Data Availability Statement: Data generated or analyzed during the study are available from the corresponding author by request.

Conflicts of Interest: The authors declare no conflict of interest.

\section{References}

1. Soltani-Sobh, A.; Heaslip, K.; Scarlatos, P.; Kaisar, E. Reliability based pre-positioning of recovery centers for resilent transportation infrastructure. Int. J. Disaster Risk 2016, 19, 324-333. [CrossRef]

2. Ghannad, P.; Lee, Y.C.; Choi, J.O. Prioritizing postdisaster recovery of transportation infrastructure systems using multiagent reinforcement learning. J. Manag. Eng. 2021, 37, 04020100. [CrossRef]

3. Edrissi, A.; Nourinejad, M.; Roorda, M.J. Transportation network reliability in emergency response. Transp. Res. Part E Logist. Transp. Rev. 2015, 80, 56-73. [CrossRef]

4. Holguín-Veras, J.; Pérez, N.; Ukkusuri, S.; Wachtendorf, T.; Brown, B. Emergency logistics issues affecting the response to katrina: A synthesis and preliminary suggestions for improvement. Transp. Res. Rec. 2007, 2022, 76-82. [CrossRef]

5. Altay, N.; Green, W.G. OR/MS research in disaster operations management. Eur. J. Oper. Res. 2006, 175, 475-493. [CrossRef]

6. McEntire, D.A.; Fuller, C.; Johnston, C.W.; Weber, R. A comparison of disaster paradigms: The search for a holistic policy guide. Public Adm. Rev. 2002, 62, 267-281. [CrossRef]

7. Rodríguez-Espíndola, O.; Albores, P.; Brewster, C. Dynamic formulation for humanitarian response operations incorporating multiple organisations. Int. J. Prod. Econ. 2018, 204, 83-98. [CrossRef]

8. Faturechi, R.; Miller-Hooks, E. Measuring the performance of transportation infrastructure systems in disasters: A comprehensive review. J. Infrastruct. Syst. 2015, 21, 04014025. [CrossRef]

9. Özcan, N.T.; Yücemen, M.S. Seismic reliability of highway transportation systems. Asce-Asme J. Risk Uncertain. Eng. Syst. Part A Civ. Eng. 2018, 4, 04018019. [CrossRef]

10. Yan, S.; Shih, Y.L. An ant colony system-based hybrid algorithm for an emergency roadway repair time-space network flow problem. Transportmetrica 2012, 8, 361-386. [CrossRef]

11. Li, S.; Teo, K.L. Post-disaster multi-period road network repair: Work scheduling and relief logistics optimization. Ann. Oper. Res. 2019, 283, 1345-1385. [CrossRef]

12. Aksu, D.T.; Ozdamar, L. A mathematical model for post-disaster road restoration-Enabling accessibility and evacuation. Transp. Res. Part. E Logist. Transp. Rev. 2014, 61, 56-67. [CrossRef]

13. Yan, S.; Lin, C.K.; Chen, S.Y. Optimal scheduling of logistical support for an emergency roadway repair work schedule. Eng. Optim. 2012, 44, 1035-1055. [CrossRef]

14. Li, S.; Ma, Z.; Teo, K.L. A new model for road work repair after natural disasters-Integrating logistics support scheduling and routing activities. Comput. Ind. Eng. 2020, 145, 106506. [CrossRef] 
15. Zhou, Y.; Liu, J.; Zhang, Y.; Gan, X. A multi-objective evolutionary algorithm for dynamic emergency resource scheduling problems. Transp. Res. Part. E Logist. Transp. Rev. 2017, 99, 77-95. [CrossRef]

16. Zhang, Z.; Wei, H.H. Modeling interaction of emergency inspection routing and restoration scheduling for postdisaster resilience of highway-bridge networks. J. Infrastruct. Syst. 2020, 27, 04020046. [CrossRef]

17. Sheu, J.B. Dynamic relief-demand management for emergency logistics operations under large-scale disasters. Transp. Res. Part. E Logist. Transp. Rev. 2010, 46, 1-17. [CrossRef]

18. Caunhye, A.M.; Nie, X.; Pokharel, S. Optimization models in emergency logistics: A literature review. Socioecon. Plann. Sci. 2012, 46, 4-13. [CrossRef]

19. Wohlgemuth, S.; Oloruntoba, R.; Clausen, U. Dynamic vehicle routing with anticipation in disaster relief. Socioecon. Plann. Sci. 2012, 46, 261-271. [CrossRef]

20. Zhang, J.H.; Li, J.; Liu, Z.P. Multiple-resource and multiple-depot emergency response problem considering secondary disasters. Expert Syst. Appl. 2012, 39, 11066-11071. [CrossRef]

21. Yan, S.; Chu, J.C.; Shih, Y.L. Optimal scheduling for highway emergency repairs under large-scale supply-demand perturbations. IEEE Trans. Intell. Transp. Syst. 2014, 15, 2378-2393. [CrossRef]

22. Orabi, W.; El-Rayes, K.; Senouci, A.B.; Al-Derham, H. Optimizing postdisaster reconstruction planning for damaged transportation networks. J. Constr. Eng. Manag. 2009, 135, 1039-1048. [CrossRef]

23. Orabi, W.; Senouci, A.B.; El-Rayes, K.; Al-Derham, H. Optimizing resource utilization during the recovery of civil infrastructure systems. J. Manag. Eng. 2010, 26, 237-246. [CrossRef]

24. Chen, A.Y.; Peña-Mora, F.; Ouyang, Y. A collaborative GIS framework to support equipment distribution for civil engineering disaster response operations. Autom. Constr. 2011, 20, 637-648. [CrossRef]

25. Yan, S.; Shih, Y.L. Optimal scheduling of emergency roadway repair and subsequent relief distribution. Comput. Oper. Res. 2009, 36, 2049-2065. [CrossRef]

26. Bíl, M.; Vodák, R.; Kubeček, J.; Bílová, M.; Sedoník, J. Evaluating road network damage caused by natural disasters in the Czech Republic between 1997 and 2010. Transp. Res. Part A Policy Pr. 2015, 80, 90-103. [CrossRef]

27. Keaton, J.; Perry, D.; Kim, P. Repair of storm-damaged slopes, Lower Mount Wilson Road, Los Angeles County, California. Transp. Res. Rec. 2011, 2204, 242-250. [CrossRef]

28. Kaviani, A.; Thompson, R.G.; Rajabifard, A.; Sarvi, M. A model for multi-class road network recovery scheduling of regional road networks. Transportation 2018, 47, 109-143. [CrossRef]

29. Sheu, J.B.; Pan, C. Relief supply collaboration for emergency logistics responses to large-scale disasters. Transp. A Transp. Sci. 2015, 11, 210-242. [CrossRef]

30. Campbell, A.M.; Vandenbussche, D.; Hermann, W. Routing for relief efforts. Transp. Sci. 2008, 42, 127-145. [CrossRef]

31. Huang, M.; Smilowitz, K.R.; Balcik, B. A continous approximation approach for assessment routing in disaster relief. Transp. Res. Part B 2013, 50, 20-41. [CrossRef]

32. Zhong, S.; Cheng, R.; Jiang, Y.; Wang, Z.; Larsen, A.; Nielsen, O.A. Risk-averse optimization of disaster relief facility location and vehicle routing under stochastic demand. Transp. Res. Part. E Logist. Transp. Rev. 2020, 141, 102015. [CrossRef]

33. Duque, P.M.; Sörensen, K. A GRASP metaheuristic to improve accessibility after a disaster. Or Spectr. 2011, 33, 525-542. [CrossRef]

34. Duque, P.A.M.; Dolinskaya, I.S.; Sörensen, K. Network repair crew scheduling and routing for emergency relief distribution problem. Eur. J. Oper. Res. 2016, 248, 272-285. [CrossRef]

35. Kim, S.; Shin, Y.; Lee, G.M.; Moon, I. Network repair crew scheduling for short-term disasters. Appl. Math. Model. 2018, 64, 510-523. [CrossRef]

36. Chen, T.; Wu, S.; Yang, J.; Cong, G.; Li, G. Modeling of emergency supply scheduling problem based on reliability and its solution algorithm under variable road network after sudden-onset disasters. Complexity 2020, 2020, 7501891. [CrossRef]

37. Lu, C.C.; Ying, K.C.; Chen, H.J. Real-time relief distribution in the aftermath of disasters-rolling horizon approach. Transp. Res. Part. E Logist. Transp. Rev. 2016, 93, 1-20. [CrossRef]

38. Sheu, J.B.; Pan, C. A method for designing centralized emergency supply network to respond to large-scale natural disasters. Transp. Res. Part. B 2014, 67, 284-305. [CrossRef]

39. Zhang, W.; Wang, N.; Nicholson, C. Resilience-based post-disaster recovery strategies for road-bridge networks. Struct. Infrastruct. Eng. 2017, 13, 1404-1413. [CrossRef]

40. Li, Z.; Jin, C.; Hu, P.; Wang, C. Relisience-based transportation network recovery strategy during emergency recovery phase under uncertainty. Reliab. Eng. Syst. Saf. 2019, 188, 503-514. [CrossRef]

41. Xu, M.; Ouyang, M.; Mao, Z.; Xu, X. Improving repair sequence scheduling methods for postdisaster critical infrastructure systems. Comput. Civ. Infrastruct. Eng. 2019, 34, 506-522. [CrossRef]

42. Chakrabortty, R.K.; Sarker, R.A.; Essam, D.L. Multi-mode resource constrained project scheduling under resource disruptions Comput. Chem. Eng. 2016, 88, 13-29. [CrossRef]

43. Brucker, P.; Drexl, A.; Möhring, R.; Neumann, K.; Pesch, E. Resource-constrained project scheduling: Notation, classification, models, and methods. Eur. J. Oper. Res. 1999, 112, 3-41. [CrossRef]

44. Baptiste, P.; Le Pape, C. Constraint propagation and decomposition techniques for highly disjunctive and highly cumulative project scheduling problems. Constraints 2000, 5, 119-139. [CrossRef]

45. Baptiste, P.; Demassey, S. Tight LP bounds for resource constrained project scheduling. Or Spectr. 2004, 26, 251-262. [CrossRef] 
46. Liess, O.; Michelon, P. A constraint programming approach for the resource-constrained project scheduling problem. Ann. Oper. Res. 2008, 157, 25-36. [CrossRef]

47. Brucker, P.; Knust, S. Linear programming and constraint propagation-based lower bound for the RCPSP. Eur. J. Oper. Res. 2000, 127, 355-362. [CrossRef]

48. Alcaraz, J.; Maroto, C. A robust genetic algorithm for resource allocation in project scheduling. Ann. Oper. Res. 2001, 102, 83-109. [CrossRef]

49. Rahman, H.F.; Chakrabortty, R.K.; Ryan, M.J. Memetic algorithm for solving resource constrained project scheduling problems. Autom. Constr. 2020, 111, 103052. [CrossRef]

50. Pinto, G.; Ben-Dov, Y.T.; Rabinowitz, G. Formulating and solving a multi-mode resource-collaboration and constrained scheduling problem (MRCCSP). Ann. Oper. Res. 2013, 206, 311-339. [CrossRef]

51. Chakrabortty, R.K.; Sarker, R.A.; Essam, D.L. Resource constrained project scheduling with uncertain activity durations. Comput. Ind. Eng. 2017, 112, 537-550. [CrossRef]

52. Hauder, V.A.; Beham, A.; Raggl, S.; Parragh, S.N.; Affenzeller, M. Resource-constrained multi-project scheduling with activity and time flexibility. Comput. Ind. Eng. 2020, 150, 106857. [CrossRef]

53. IBM ILOG CPLEX Optimization Studio. Available online: https://www.ibm.com/products/ilog-cplex-optimization-studio/ details (accessed on 20 December 2020). 